\title{
Dinámica relacional de las actividades recreativas en el Área de Protección de Flora y Fauna Nevado de Toluca, México: El enfoque del Análisis de Redes Sociales
}

\author{
Nadinne Ivette González-Romero* Tizbe T. Arteaga-Reyes** \\ Universidad Autónoma del Estado de México (México)
}

Stéphane Héritier****

Université Grenoble-Alpes (Francia)

Humberto Thomé-Ortiz****

Universidad Autónoma del Estado de México (México)

Leopoldo Galicia******

Universidad Nacional Autónoma de México (México)

\begin{abstract}
Resumen: La gestión de las actividades recreativas en Áreas Naturales Protegidas es compleja por el número de actores sociales que aprovechan y administran los recursos naturales con actividades, intereses y necesidades distintas. El objetivo del estudio fue analizar la dinámica relacional entre los actores sociales involucrados en tres Unidades Socio-Ecológicas, y sus implicaciones en el manejo de las actividades recreativas en el Área de Protección de Flora y Fauna Nevado de Toluca, México. A partir de una revisión de literatura, entrevistas semiestructuradas y Análisis de Redes Sociales se encontró que los actores sociales presentes, no son suficientes para un buen manejo de las actividades recreativas. La principal función de todos los actores sociales es la conservación de recursos naturales, pero también asumen funciones para el manejo de las actividades recreativas. La dinámica entre actores sociales presenta lazos débiles e intermitencia en las relaciones debido a la ausencia de vínculos institucionalizados y metas comunes. Es necesario desarrollar redes de colaboración donde los actores asuman corresponsabilidades y acciones conjuntas para la planeación y manejo de las actividades recreativas.
\end{abstract}

Palabras Clave: Actores sociales; Análisis de Redes Sociales; Conservación; Dinámica relacional; Manejo; Recreación.

Relational dynamics of recreational activities in the Nevado de Toluca Flora and Fauna Protection Area, Mexico: A Social Network Analysis approach

Abstract: The management of recreational activities in Natural Protected Areas is complex due to the number of stakeholders that use and manage natural resources, their varying activities, interests and needs. The aim of the study was to analyse the relational dynamics between stakeholders involved in three Socio-Ecological Units, and their implications in the management of recreational activities in the Nevado de Toluca Flora and Fauna Protected Area, Mexico. From literature review, semi-structured interviews and application of Social Network Analysis tools, it was identified that not all the stakeholders that should be involved for efficient management of recreational activities are effectively included. Although their main function is the conservation of natural resources, they also assume functions for the management of recreational activities. They present weak ties and lack of consistency in their relationships, due to the absence of institutionalized links and common goals. It is necessary to move towards collaboration networks where stakeholders assume joint responsibilities and actions for the planning and management of recreational activities.

Keywords: Stakeholders; Social Network Analysis; Conservation; Relational dynamics; Management; Recreation.

\footnotetext{
Universidad Autónoma del Estado de México (México); E-mail: meipax13@hotmail.com; https://orcid.org/0000-0002-8678-1906

** Autora para correspondencia (México); E-mail: tizbe@hotmail.com ; https://orcid.org/0000-0001-7803-6749

*** Université Grenoble-Alpes (Francia); E-mail: step_heritier@hotmail.com ; https://orcid.org/0000-0002-0993-9933

**** Universidad Autónoma del Estado de México (México); E-mail: humbertothome@hotmail.com ; https://orcid.org/0000-0002-6714-3490

****** Universidad Nacional Autónoma de México (México); E-mail: lgalicia@igg.unam.mx ; http://orcid.org/0000-0002-5808-6471
} 


\section{Introducción}

La ciencia y práctica de la conservación se han basado en conocimientos científicos y en una comprensión cada vez más sofisticada de los procesos ecológicos, lo que ha minimizado la importancia de los procesos sociales dentro de la gestión de los espacios naturales (Brechin, Wilshusen, Fortwangler y West, 2002; Maass et al., 2010; Ban et al., 2013; Bennett et al., 2017). En las Áreas Naturales Protegidas (ANP), la comprensión de los mundos físico y social requiere examinar las relaciones entre los elementos que componen los fenómenos en estudio (Baggio, Scott y Cooper, 2010). Sin embargo, la investigación científica en relación con los conocimientos tradicionales o autóctonos, a menudo ha demostrado la complejidad de las interrelaciones y de las dinámicas de la coevolución entre los sistemas ecológicos y sociales, aspecto que ha llevado a la validación de la noción de sistema socio-ecológico, o socio-ecosistema (Toledo, 1996; Leff, 2000; Vandermeer y Perfecto, 2003; Toledo y Barrera-Bassols, 2011; Maass et al. 2016).

Muchas de las ANP (por ejemplo, los parques nacionales o ANP de categorías IV, V y VI de la UICN Unión Internacional para la Conservación de la Naturaleza) tienen como objetivo mantener los beneficios que proporcionan los ecosistemas naturales entre los que destacan servicios ecosistémicos culturales como la recreación ${ }^{1}$ (Stolton, 2010). A su vez, la gestión deficiente del turismo y la recreación (Pulido y López, 2012) impactan negativamente en los recursos naturales y culturales (Leung, Spenceley, Hvenegaard y Buckley, 2015). La complejidad es mayor en situaciones como el Área de Protección de Flora y Fauna Nevado de Toluca - incluida en la categoría VI de la UICN, que corresponde a un Área Protegida con uso sostenible de los recursos naturales - donde habitan comunidades agrarias que necesitan desarrollar actividades económicas. En este caso, las actividades recreativas dependen de un subsistema social formado por una diversidad de actores sociales con objetivos, funciones, necesidades e intereses heterogéneos. Las relaciones entre esos agentes sociales repercuten en la gestión de las actividades y en la forma en que se utilizan y conservan los recursos para garantizar la sostenibilidad del área protegida (Fig. 1).

El estudio de las relaciones sociales ha cobrado importancia en el ámbito de la conservación (Guerrero, McAllister, Corcoran y Wilson, 2013) y del turismo (Dedeke, 2017), pues se ha identificado como un factor clave en la valoración de la capacidad de acción de cualquier territorio, debido a que existe una relación directa entre el grado de desarrollo turístico ${ }^{2}$ y la dinámica relacional de los actores locales (Merinero y Pulido, 2009; Merinero y Zamora, 2009). La dinámica relacional implica tanto el análisis estructural del entramado de actores sociales como del contenido de las relaciones que se establecen entre ellos, generando información relevante para la planificación e implementación de estrategias destinadas al fortalecimiento de la participación entre los diferentes actores sociales (Burgos, 2014).

Figura 1. Problemática del manejo de actividades recreativas en ANP.

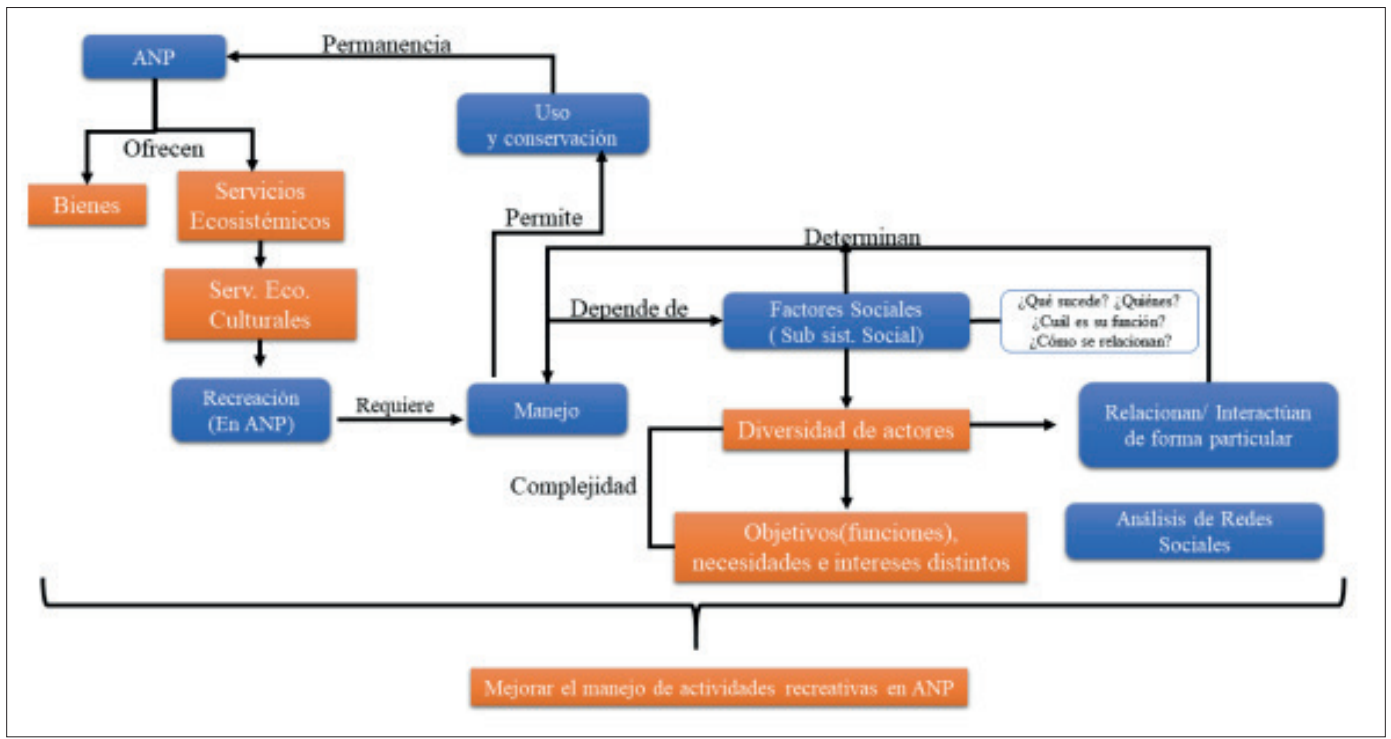

Fuente: González (2018). 
El estudio de las relaciones entre los actores sociales implicados en el turismo se basa, entre otras cosas, en el Análisis de las Redes Sociales (ARS) (Burgos, 2014). La literatura científica aborda la dinámica en la que se constituye la gestión de las actividades de ocio, considerando que la actividad turística se define por las relaciones entre los elementos que la integran (Artesi, 2007). De esta manera, el ARS proporciona a la investigación turística un conjunto de métodos y herramientas para comprender patrones, estructuras y vínculos entre las categorías de actores sociales (Casanueva, Gallego y García-Sánchez, 2016). Por ejemplo, se ha utilizado para explicar la dinámica de las relaciones socioecológicas en áreas turísticas (Martini y Buffa, 2015; Merinero y Pulido, 2009) resaltando la importancia de las relaciones sociales para garantizar el desarrollo sostenible del turismo (Vargas y Rodríguez, 2014), para identificar redes de colaboración científica en el campo turístico (van der Zee y Vanneste, 2015), o para analizar la configuración de las líneas de investigación dentro de los estudios turísticos (Casanueva et al., 2016). El ARS ha apoyado al entendimiento de redes de competencia en el sector turístico (de Oliveira, Reis, Cabral y Wittmann, 2012; Nordin, 2003; van der Zee Gerrets y Vanneste, 2017), la forma en que fomenta los procesos de desarrollo local, sustentable y endógeno (Artesi, 2007), y la forma en que se estructuran las redes de actores políticos, de negocios y cooperación (van der Zee y Vanneste, 2015). En México se han utilizado para comprender el desarrollo turístico en destinos emergentes y para la generación de propuestas de mejora de la política pública (Rodríguez, Pulido, Vargas, y Shaadi, 2018), así como para la reflexión sobre la importancia de fortalecer las relaciones entre actores sociales (Vargas y Rodríguez, 2014). Sin embargo, han sido poco exploradas en el manejo conjunto de actividades recreativas en ANP.

El manejo de los recursos naturales en ANP es resultado de procesos sociales que son motivados por distintas necesidades (Mardones, 2017). En este sentido, la dimensión social influye en las dinámicas de los ecosistemas y en su capacidad para suministrar distintos tipos de servicios ecosistémicos (Endter-Wada, Blahna, Krannich y Brunson, 1998; Bennett et al., 2017). Las decisiones que los sistemas sociales (en todos los niveles) toman respecto a su gestión modifican el funcionamiento de los ecosistemas (Balvanera, Arias-González, Rodríguez-Estrella, Almeida-Leñero y Schmitter-Soto, 2016), en un contexto en el que las relaciones no son ni lineales ni mecánicas, sino que adoptan la forma de un sistema complejo de múltiples interacciones (Jiménez Martínez, 2005).

El Área de Protección de Flora y Fauna Nevado de Toluca (APFFNT) es un socio-ecosistema ${ }^{3}$ en el cual ocurren diferentes dinámicas sociales para el aprovechamiento de sus cualidades estéticas con propósitos recreativos. Se compone de Unidades Socio-Ecológicas (USE) ${ }^{4}$ que comparten características biofísicas, acciones de conservación y actividades recreativas, en donde confluyen diversos tipos de tenencia de la tierra ${ }^{5}$ : ejidal, comunal, federal y propiedad privada, lo que hace que el manejo de las actividades recreativas se desarrolle en contextos social y ecológicamente frágiles y complejos (González-Romero, Galicia, Arteaga-Reyes, Thomé-Ortiz y Héritier, 2018). El objetivo de la presente investigación fue analizar la dinámica relacional (funciones, estructura, naturaleza y calidad de las relaciones) entre los actores sociales involucrados en las actividades recreativas en tres Unidades Socio-Ecológicas, y sus implicaciones en el manejo de las actividades recreativas en el APFFNT. El análisis de dichas relaciones tiene por objeto mejorar el manejo de las actividades recreativas para evitar el deterioro de los ecosistemas y contribuir al objetivo de las ANP de ser disfrutadas y protegidas.

\section{Métodos}

\subsection{Zona de estudio}

El Área de Protección de Flora y Fauna Nevado de Toluca (APFFNT) es una de las ANP más significativas en el Estado de México; que comprende el volcán Xinantécatl, la cuarta cumbre más alta de México (4,680 m. de altitud) y constituye un área biogeográfica relevante a nivel nacional (Diario Oficial de la Federación [DOF], 2016). Sus ecosistemas son de vital importancia debido a los servicios ecosistémicos - hidrológicos y forestales - que presta a la zona centro de México (Vargas, 1997; Comisión Nacional de Áreas Naturales Protegidas [CONANP], 2013; DOF, 2016), pues asegura el abastecimiento de agua de la ciudad de Toluca (más de 2 millones de habitantes), parte de la Ciudad de México (la cuarta metrópolis más grande del mundo), y del estado de Guerrero. Contribuye a la "conservación de los ecosistemas forestales, desde el zacatonal alpino hasta los bosques de coníferas y los bosques templados" de encino o latifoliada (DOF, 2016, p. 12), mientras que algunos sectores - en particular los estudiados en este artículo - resultan atractivos turísticamente para las concentraciones urbanas cercanas. Se seleccionaron tres USE del APFFNT (Mapa 1) en donde coexisten acciones de conservación y actividades recreativas: i) "El Cráter" considerado la zona núcleo; ii) El Parque de "Los Venados" y iii) 
El Parque Ecoturístico "La Ciénega", ubicados en la zona de amortiguamiento, en la subzona de Uso Público y Áreas de Turismo Sustentable, en territorios del Ejido de San Juan de las Huertas (ESJH) y el Ejido de Loma Alta (ELA).

\section{Mapa 1: Ubicación del socioecosistema Área de Protección de Flora y Fauna Nevado de Toluca (APFFNT) y sus Unidades Socio-Ecológicas (USE).}

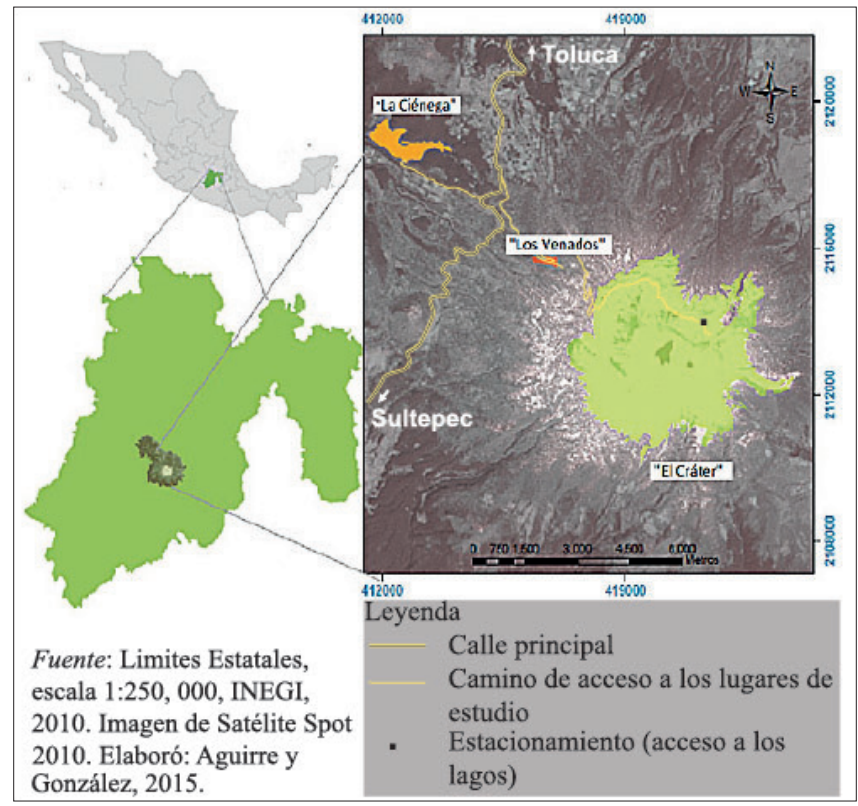

Fuente: Adaptado de González (2018).

Los criterios de selección para las unidades de observación fueron: a) ser de los principales sitios de visitación turística del APFFNT, b) estar localizados en la principal ruta de acceso, c) el tipo de propiedad de la tierra; y d) el tipo de desarrollo y administración de la actividad recreativa. Estos tres sitios se distinguieron por sus características ecológicas: en "El Cráter", un ecosistema de gran altitud asociado a los dos lagos de montaña de la zona del cráter; en "La Ciénega", un humedal con una población de ajolote (Ambystoma rivularis) en peligro de extinción y una población vegetal de oyamel (Abies religiosa) y oyamel-pino (Abies-Pinus). Por último, "Los Venados", ubicado en el camino de acceso al cráter, está sujeto a una amplia presión turística que requiere un amplio control de la vegetación boscosa - ocote (Arracacia rigida), pino amarillo (Pinus ponderosa), pino chino (Pinus hartwegii) - (CONANP, 2013; CONANP, 2016) - en un sector con poca agua. Estudios previos identificaron que las USE comparten características biofísicas que les brinda el ecosistema de montaña, como el rango altitudinal (superior a 3,000 m sobre el nivel del mar), la "vegetación alpina" (Ceballos, 2011, p. 38) y los lagos conocidos como "Laguna del Sol" y "Laguna de la Luna", siendo el recurso hídrico el factor biofísico que produce la visitación en los tres "puntos turísticos", sólo diferenciado por la temporalidad (González-Romero et al., 2018). Tanto las particularidades como las similitudes de estas tres USE, permitieron un análisis comparativo del manejo de actividades recreativas, a partir de la dinámica relacional que existe en el APFFNT.

\subsection{Análisis de Redes Sociales (ARS)}

La investigación incorporó datos cualitativos y cuantitativos a partir de información documental y referentes empíricos. A partir de la revisión de literatura se contextualizó la dinámica relacional (Merinero y Pulido, 2009; Vargas y Rodríguez, 2014; Rodríguez et al., 2018), el Análisis de Redes Sociales (Hanneman y Riddle, 2000; Wasserman y Faust, 2013; Crona y Bodin, 2006), redes en turismo (Casanueva et al., 2016; Scott, Baggio y Cooper, 2008; van der Zee y Vanneste, 2015) y redes de actores 
sociales en ANP (Calvet-Mir, Maestre-Andrés, Molina y van den Bergh, 2015; De la Mora-De la Mora, 2015; Mardones, 2017). El trabajo de campo y las entrevistas (apoyadas en los instrumentos de ARS diseñados para esta investigación) permitieron definir a los actores sociales, sus funciones y relaciones.

Para los instrumentos de ARS se determinaron variables atributivas (nombre, institución que representa, sitio de injerencia, sector, tipo, ámbito de acción y función dentro del sitio) que permitieron definir a los actores sociales a partir de sus características o cualidades específicas. Asimismo, se determinaron variables estructurales (tipo, objetivo, frecuencia, carácter, calidad, modo y medio por el que se da la relación) que a su vez apoyaron la identificación de los vínculos entre los actores sociales. Se diseñaron dos instrumentos, uno para los actores sociales de gestión de la APFFNT, empresas de alimentos y bebidas, y para las empresas que ofertan actividades recreativas especializadas en el APFFNT, y otro para los visitantes.

Debido a que las características de los datos relacionales imposibilitan realizar algún tipo de muestreo, es necesario contar con información de todos los actores sociales y todos los lazos que componen la red social (Verd Pericás y Martí Olivé, 1999). Asimismo, las investigaciones de análisis relacionales no requieren de una representatividad de elementos de una población, sino una cuidadosa y controlada selección de sujetos con ciertas características bajo un enfoque cualitativo, obteniendo los casos que interesan al investigador y que permiten la recolección y análisis de los datos (Rodríguez et al., 2018). Por lo tanto, en este caso no fue necesaria una muestra estadísticamente representativa. En este sentido, la determinación de la muestra se realizó en dos grupos, el primero cuando el número de actores sociales era reducido y fácilmente identificable, al cual se aplicaron los criterios de Laumann, Marsden y Prensky (1983) considerando el IV que se refiere al método de la "bola de nieve" (Goodman, 1961) y el V en función de las actividades en que los actores sociales participan conjuntamente.

Para el segundo grupo, con un número mayor de actores sociales, se aplicó el enfoque nominalista de Laumann et al. (1983), donde los límites de la red los fija el propio investigador (Wasserman y Faust, 2013). En este grupo se encontraron los visitantes y los prestadores de servicios turísticos especializados (PSTE), los cuales se identificaron previamente con base en la literatura, corroborándose en campo los tipos de visitantes y las principales actividades que realizan. Para ello se aplicaron 20 entrevistas semiestructuradas por cada tipo de actividad con un total de 140 entrevistas entre las tres USE (caminata, senderismo, montañismo, ciclismo, correr, día de campo y convivencia familiar). Las PSTE en el APFFNT se identificaron en el trabajo de campo, por medio de la consulta de los libros de registro de la Comisión Estatal de Parques Naturales y de la Fauna (CEPANAF) y a través de la red social más utilizada por los visitantes en el periodo de la investigación (Facebook); se descartaron aquellas que solo ofertaban transportación y se consideraron las que ofertaban actividades de montaña; solamente cinco colaboraron. La aplicación de las entrevistas e instrumentos se realizó entre octubre y noviembre de 2016 en la época del año con baja visitación y entre enero y febrero de 2017, la temporada de mayor visitación; en ambos casos los días establecidos fueron el último domingo del mes, en horarios de atención a visitantes (8:00-17:00 horas).

Ambos instrumentos integraron los datos del actor y los vínculos; se codificaron utilizando medidas binarias de relaciones ampliamente utilizadas en ARS (Hanneman y Riddle, 2000), asignando 1 a las relaciones o lazos existentes y 0 a las relaciones ausentes; y medidas nominales de categoría múltiple (Ramírez y Gómez, 2016; Wasserman y Faust, 2013). Se solicitó a los informantes que, de acuerdo con su experiencia, de una lista de actores sociales eligieran para cada uno qué categoría describía mejor su relación con cada actor, especificando el lazo que tenían con éstos. Los instrumentos se validaron y se realizó una prueba piloto en un lugar con características similares a los sitios de estudio.

El análisis de las relaciones entre los actores sociales vinculados a las áreas protegidas ha utilizado metodologías cualitativas (De la Mora-De la Mora, 2015), así como el análisis de la estructura de las redes de relaciones entre los actores sociales (Cruz y Velázquez, 2020). En el caso del APFFNT, el análisis de las relaciones implicó la comprensión de posiciones, roles e influencia de los diferentes actores sociales, a partir de índices de densidad (porcentaje de relaciones existentes entre las posibles de toda la red); centralidad (cantidad de actores sociales a los que un actor está directamente unido); intermediación (posibilidad de un actor para intermediar las comunicaciones entre otros), y centralización (conexiones directas entre actores sociales) (Rendón, Aguilar, Muñoz y Altamirano, 2007). Para profundizar en las relaciones se realizó el Análisis de Contenidos de las Redes Sociales (Merinero y Pulido, 2009), que permitió obtener información de las características de las relaciones y particularmente la naturaleza (tipo de relaciones) y calidad (fuerte, débil o de conflicto). La información se sistematizó por medio de una base de datos en Excel con matrices de modo 1 y modo 2, posteriormente se introdujeron en el software UCINET 6.2 para calcular las medidas de centralidad, y después con el software NetDraw, 
se construyeron gráficos donde los nodos representan a los actores sociales y las líneas a los vínculos o relaciones.

\section{Resultados}

\subsection{Los actores sociales y su papel en las actividades recreativas en el APFFNT}

Las actividades recreativas por su naturaleza social implican una constante interacción entre las diversas partes involucradas que pueden ser personas, colectividades, organizaciones o instituciones (Dredge, 2006; van der Zee et al., 2017). Entre los actores sociales relacionados con el manejo de actividades recreativas en el APFFNT se encuentran (Tabla 1) instituciones gubernamentales de los tres niveles de gobierno (federal, estatal y municipal), encargadas de cuestiones ambientales y de atención médica pre-hospitalaria; instituciones académicas (enfocadas en acciones de conservación de recursos naturales y el aprovechamiento turístico del territorio); ejidatarios (poseedores de las tierras), y actores sociales temporales entre los que se encuentran visitantes y empresas que ofertan actividades recreativas, así como alimentos y bebidas. Por su ubicación geográfica, el Parque "Los Venados" es punto de acceso para llegar a "El Cráter", por lo que hay actores sociales que se ubican en ambos sitios y por ende están en comunicación. En contraste, "La Ciénega" está más alejada y el contacto con los actores sociales de las otras dos USE es extremadamente débil.

Tabla 1: Actores sociales y sus funciones en tres USE del APFFNT

\begin{tabular}{|c|c|c|c|c|c|}
\hline Actor & Cráter & Venados & Ciénega & Función principal & Función dentro de las actividades recreativas \\
\hline CONANP & $\checkmark$ & $\checkmark$ & $\checkmark$ & $\begin{array}{l}\text { Conservar el patrimonio natural y promover el } \\
\text { desarrollo sustentable }\end{array}$ & $\begin{array}{l}\text { Establecer normas para evitar daños en el ecosistema } \\
\text { Autorizar las diferentes actividades turístico-recreativas o la venta de alimentos y } \\
\text { artesanias dentro del ANP, y vigilar que la aplicación de las reglas administrativas } \\
\text { permita un turismo ambientalmente responsable sin alterar o perturbar los espacios } \\
\text { naturales. }\end{array}$ \\
\hline CEPANAF & $\checkmark$ & $\checkmark$ & $\mathbf{x}$ & Administración y conservación del ANP & $\begin{array}{l}\text { - Prohibir el paso de los visitantes hacia las lagunas en vehículos, vigilar que no entren a } \\
\text { la zona núcleo con mascotas y auxiliar a los visitantes en caso de emergencia o en su } \\
\text { caso solicitar apoyo a otras dependencias de acuerdo a la gravedad de la situación. }\end{array}$ \\
\hline PAM-CES & $\checkmark$ & $\checkmark$ & $\mathbf{x}$ & Brindar seguridad a los visitantes de alta montaña & $\begin{array}{l}\text { - Brindar seguridad a los visitantes de alta montaña } \\
\text { Vigilar que los visitantes cumplan con d reglamento del ANP y brindar primeros } \\
\text { auxilios en caso de algún accidente. }\end{array}$ \\
\hline SUEM & $\checkmark$ & $\checkmark$ & $\mathbf{x}$ & Atención médica pre-hospitalaria & - Atender urgencias de los visitantes \\
\hline GR & $\checkmark$ & $\mathbf{x}$ & $\mathbf{x}$ & Atención médica pre-hospitalaria & - Búsqueda, rescate y traslado de personas extraviadas o con lesiones mayores. \\
\hline PROESNEVADO & $\checkmark$ & $\checkmark$ & $\mathbf{x}$ & $\begin{array}{l}\text { La conservación del ANP, la administración, la gestión, } \\
\text { investigación y la generación de vínculos. }\end{array}$ & $\begin{array}{l}\text { - Trabajo conjunto para evitar que los visitantes generen impactos negativos en los } \\
\text { recursos naturales }\end{array}$ \\
\hline MAT & $\checkmark$ & $\mathbf{x}$ & $\mathbf{x}$ & & \\
\hline MAZ & $\checkmark$ & $\checkmark$ & $\checkmark$ & Cuidado de los recursos naturales & - Colaborar con las brigadas de búsqueda y rescate cuando se presenta alguna \\
\hline PCT & $\checkmark$ & $\mathbf{x}$ & $\mathbf{x}$ & \multirow{2}{*}{$\begin{array}{l}\text { Salvaguardar la integridad fisica en la vida, los bienes y } \\
\text { el entorno, prevención, auxilio y recuperación }\end{array}$} & contingencia con los visitantes o con los recursos naturales. \\
\hline PCZ & $\checkmark$ & $\checkmark$ & $\checkmark$ & & \\
\hline ITT & $\checkmark$ & $x$ & $\mathbf{x}$ & $\begin{array}{l}\text { Investigación, acciones para la conservación y } \\
\text { preservación de los recursos naturales }\end{array}$ & - Gestión de acciones para controlar el flujo e impacto de los visitantes \\
\hline UAEMex & $\checkmark$ & $\checkmark$ & $x$ & Investigación & $\begin{array}{l}\text { - Asesoramiento sobre el potencial de los recursos naturales para las actividades } \\
\text { recreativas }\end{array}$ \\
\hline ESJH & $x$ & $\checkmark$ & $x$ & Administración y toma de decisiones & $\begin{array}{l}\text { - Cobro de la cuota de acceso } \\
\text { Dar mantenimiento y vigilancia }\end{array}$ \\
\hline ELA & $\mathbf{x}$ & $\mathbf{x}$ & $\checkmark$ & & - Atender las necesidades de los visitantes \\
\hline PSTE & $\begin{array}{l}x \\
\checkmark\end{array}$ & $\begin{array}{l}\checkmark \\
\checkmark\end{array}$ & $\mathbf{x}$ & $\begin{array}{l}\text { Ofertar servicios de alimentos y bebidas } \\
\text { Ofertar servicios turísticos especializados(alpinismo, } \\
\text { senderismo etc) }\end{array}$ & - Oferta de servicios de alimentos y bebidas y de actividades especializadas \\
\hline Visitantes & $\checkmark$ & $\checkmark$ & $\checkmark$ & Realizar actividades recreación & - Realizar actividades recreación \\
\hline \multicolumn{6}{|c|}{$\begin{array}{l}\text { Acrónimos } \\
\text { CONANP: Comisión Nacional de Áreas Naturales Protegidas, CEPANAF: Comisión Estatal de Parques Naturales y de la Fauna, PAM-CES: Policía de Alta Montaña de la Comisión Estatal de Seguridad, SUEM: Servicio de } \\
\text { Urgencias del Estado de México, GR: Grupo Relámpagos, PROESNEVADO: Programa de Recuperación y Manejo Sustentable del Nevado de Toluca, MAT: Medio Ambiente Toluca, MAZ: Medio Ambiente Zinacantepec, } \\
\text { PCT: Protección Civil Toluca, PCZ: Protección Civil Zinacantepec, ITT: Instituto Tecnológico de Toluca, UAEMex Universidad Autónoma del Estado de México, ESJH: Ejido de San Juan de las Huertas, ELA: Ejido de Loma } \\
\text { Alta, AyB: Empresas que ofertan servicios de al imentos y bebidas, PSTE: Empresas prestadoras de servicios turísticos especializados. }\end{array}$} \\
\hline
\end{tabular}

Fuente: González (2018).

La Tabla 1 muestra que la mayoría de los agentes sociales protegen los recursos endógenos. Algunos (por ejemplo, CONANP y CEPANAF) están atentos a los mecanismos generales de conservación, mientras que otros se preocupan por las dimensiones estratégicas (Proesnevado) o las estrategias de control de los recursos naturales (MAZ o MAT, por ejemplo). Otros (ejidos, ITT, PAM-CES) concentran su acción 
en la gestión de las actividades de ocio, protección y control de los visitantes para tratar de regular (con diferentes grados de éxito) el aumento de los flujos de visitantes, en particular durante los fines de semana y en la temporada de invierno. Además, las instancias rectoras para planificar y desarrollar las actividades recreativas, así como los actores sociales que hacen presencia tanto en temporada alta (invernal con alto flujo de visitantes) como en temporada baja (verano con bajo flujo de visitantes) se encuentran desvinculadas en estos territorios. Sin embargo, en algunas ocasiones se reflejan aún más vacíos, ya que la presencia de los actores sociales es intermitente y está en función de la temporada y el flujo de visitantes.

\subsection{Influencia de la estructura de las redes y posición de los actores sociales sobre las relaciones}

En las tres USE el mayor número de relaciones se presentan en el centro de la red entre los actores sociales que controlan las actividades recreativas. En la periferia se observan los visitantes como actores sociales más lejanos, con vínculos mínimos para el pago de acceso o en ocasiones para el uso de algún servicio como alimentos o sanitarios (Fig. 2). Las PSTE presentan vínculos escasos con los demás actores sociales, ya que a pesar que la Regla 9 del Capítulo II del Programa de Manejo establece que se requiere "la autorización de la Secretaría de Medio Ambiente y Recursos Naturales (SEMARNAT) por conducto de la Comisión Nacional de Áreas Naturales Protegidas (CONANP) para realizar (...) actividades turístico-recreativas dentro de Áreas Naturales Protegidas en todas sus modalidades" y/o "actividades comerciales (venta de alimentos y artesanías)" (DOF, 2016, p. 234), ninguna empresa ${ }^{6}$ que está obteniendo beneficios económicos a partir de los servicios ambientales del ANP ha gestionado algún permiso ante las instancias correspondientes. Los vínculos de unas pocas empresas se limitan a un registro en el diario de CEPANAF sobre cuántas personas ingresan a la zona en grupo y el responsable de éste en caso de que se presente algún imprevisto.

Figura 2: Grafos de redes por Unidades Socio-Ecológicas en el APFFNT.

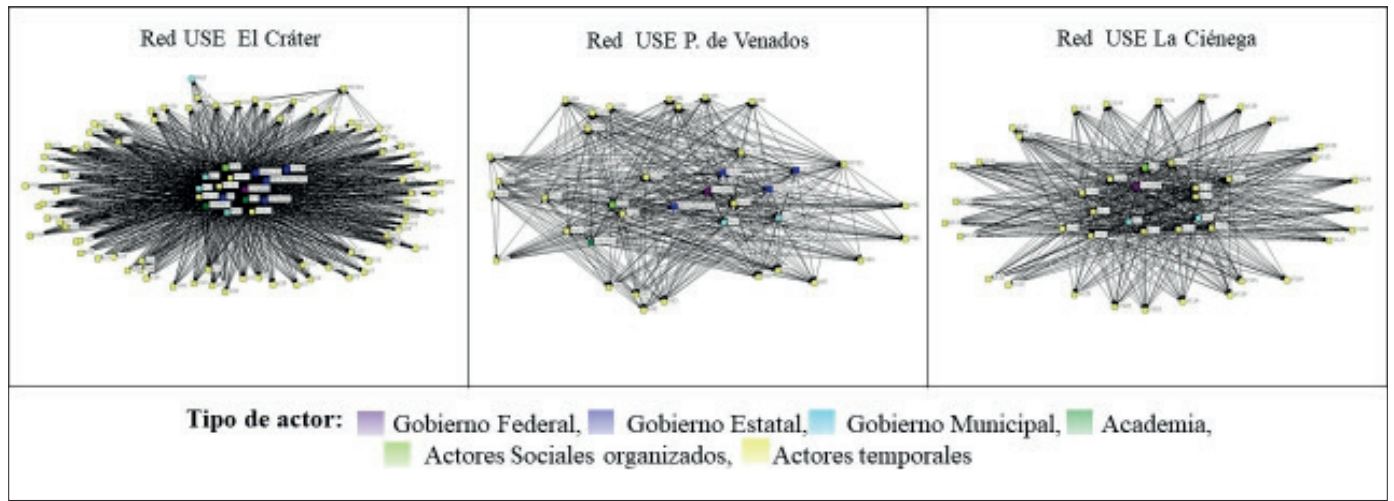

Fuente: Adaptado de González (2018).

La Figura 2 muestra la estructura de las relaciones entre los diferentes actores implicados en la actividad turística. Ello permite observar la lejanía entre recreación-conservación. Al centro se localizan los actores que administran los recursos naturales y manejan actividades recreativas. En la periferia los visitantes y prestadores de servicios.

Si se considera que las actividades recreativas se representan principalmente por los visitantes, de no ser por el pago de acceso, habría una desvinculación entre las actividades recreativas y los actores sociales encargados del manejo de los recursos en el APFFNT. Los visitantes dentro de las USE determinan el tipo de relación y el actor con el que se relacionan de acuerdo con el tipo de actividad que realizan (caminata, día de campo, senderismo, alpinismo, correr, acampar, etc.), ya que el visitante que va por medio de PSTE para practicar alpinismo o senderismo se desvincula completamente de los actores sociales locales, puesto que el pago del recorrido incluye la entrada, la actividad y en ocasiones un refrigerio. La lejanía que muestran los visitantes en las tres USE se debe a que la forma actual en 
la que se manejan las actividades recreativas en el APFFNT la cual no implica ninguna relación con los demás actores sociales. La pregunta es: ¿si esta lejanía o disociación pone en peligro la continuidad de los servicios del ecosistema cultural en el APFFNT, o si se puede lograr un equilibrio entre el uso de los recursos naturales y la conservación?

\subsection{Densidad, centralización, centralidad e intermediación}

Los resultados de la Tabla 2 muestran que la USE "El Cráter" posee la mayor densidad con el mayor número de actores sociales y relaciones. Esta zona ha sido declarada como la "zona núcleo" en los documentos de manejo ya que se considera de mayor importancia ecológica, y al mismo tiempo es la zona más atractiva para los visitantes. Además de que es un sitio administrado por el gobierno donde se encuentran vínculos institucionales preestablecidos.

Tabla 2: Indicadores de las redes y las relaciones entre los actores sociales involucrados en el manejo de actividades recreativas en el APFFNT

\section{CRÁTER VENADOS CIÉNEGA}

Densidad

Centralización (red)

Centralidad de

entrada

Centralidad de

Salida

Intermediación
27.684

$25.34 \%$

ESJH

$10.8 \%$

CONANP

$48.8 \%$

ESJH

25.63
24.659

$18.96 \%$

ESJH

$15.4 \%$

CONANP

$47.5 \%$

ESJH

20.14
20.886

$27.47 \%$

ELA

$11.6 \%$

PCZ

$53.4 \%$

ELA

27.57

Subtítulos: ESJH = Ejido de San Juan de las Huertas; ELA = Ejido de Loma Alta; PCZ = Protección Civil Zinacantepec; CONANP = Comisión Nacional de Áreas Naturales Protegidas

Fuente: González (2018).

La Tabla 2 muestra los roles e influencia de cada actor en la red, reflejando el porcentaje de relaciones de toda la red (densidad), la cantidad de actores sociales o relaciones a los que un actor está directamente unido (centralidad); posibilidad que tiene un actor para intermediar las relaciones entre otros actores (intermediación), así como las conexiones directas entre actores sociales (centralización).

En contraste, la administración ejidal de la USE "La Ciénega" mostró la densidad más baja con pocos actores sociales que intervienen en la red y limitadas relaciones entre ellos, con un tipo de administración local por parte del ELA. Lo anterior, sugiere que dentro de una misma ANP se presentan distintos contextos para el manejo, e implica que las estrategias que se deben aplicar para el desarrollo de programas o proyectos para las actividades recreativas sean particulares y no generalizadas. En este caso, el desarrollo de este sitio forma parte de un contexto general de gestión de áreas protegidas favorable al desarrollo del turismo sostenible (Franco-Maass, Osorio-García, Nava-Bernal y Regil-García, 2009; Rodríguez Zermeño y Zizumbo Villarreal, 2009; Vallejo Valencia y Osorio García, 2013; Esquivel Rios, Cruz Jiménez, Zizumbo Villarreal, y Cadena Inostroza, 2014; CONANP, 2016; González-Romero et al., 2018). Es probable que esta debilidad de los vínculos con otros actores frene el desarrollo del turismo, ya que las investigaciones han demostrado la importancia de la cohesión de los actores sociales en términos de gestión y desarrollo sostenible (Baggio et al., 2010). 
El nivel de centralización es bajo en los tres casos y muestra que no hay una fuerza dominante que se concentre en un solo actor, sino que se distribuye uniformemente (Calvet-Mir et al., 2015), lo que representa una ventaja si se considera que redes no centralizadas como en el caso de las tres USE muestran madurez (Rendón et al., 2007). La centralidad recae, principalmente, en los ESJH y ELA; esto significa que poseen atributos que los ubican como actores sociales de prestigio, pues los otros actores acuden a ellos como poseedores de las tierras y como figura jurídica con autonomía para el manejo y gestión de sus recursos naturales. El mayor grado de centralidad de salida recae en la CONANP que se presenta como un actor líder y desarrolla un papel clave en el sitio, debido a que tiene la responsabilidad de la Dirección del ANP como autoridad normativa de los actos de autoridad (permisos, concesiones y vigilancia). Por otra parte, en "La Ciénega" el mayor grado de centralidad de salida lo refleja Protección Civil Zinacantepec (PCZ) por el apoyo que les ha brindado a los administradores en algunas contingencias ambientales y por la imagen que tienen los visitantes como una institución a la que se puede acudir en caso de alguna contingencia. El mayor grado de intermediación en las tres USE se presenta con los ejidos debido a que son el actor con más prestigio; además de ser los actores sociales intermediarios, quienes tienen la responsabilidad del manejo de las USE.

\subsection{Naturaleza y calidad de las relaciones}

Se identificó que la naturaleza de las relaciones entre los actores sociales es de apoyo, presentándose principalmente en momentos de contingencia en temporada invernal para intercambiar información y atender emergencias. Para ello, se vinculan de forma directa sin intermediarios, mayormente de palabra y escasamente a través de oficios, solicitando la colaboración de algunas instancias gubernamentales con una mínima coordinación, aunado a que la mayoría no comparten metas institucionales ni objetivos de manejo; resalta que sólo se vinculan para prevenir percances y no para planificar o regular las actividades recreativas.

La calidad de las relaciones es débil cuando son puntuales, simplemente para atender lo necesario, lo que implica poca o casi ninguna coordinación entre los actores sociales debido a que no comparten metas comunes. Las relaciones fuertes se presentan entre las instituciones gubernamentales que tienen objetivos en común y donde las relaciones se encuentran mayormente formalizadas. Las relaciones de conflicto se exteriorizan principalmente porque los visitantes no acatan las reglas establecidas como no extraer flora del lugar, la entrada con vehículos o mascotas a la zona de "El Cráter". A pesar de que la mayoría de los actores sociales tiene disposición de trabajar con aquellos que no tienen vínculos, existe desconfianza por experiencias negativas previas. Un factor importante que influye en las relaciones dentro de la dinámica relacional de las USE es la baja frecuencia de las relaciones, ya que solo se entablan vínculos en temporadas específicas como nevadas o días de mayor visitación en los sitios. Los únicos actores sociales con los que tienen una relación permanente son las instituciones del ámbito forestal y académico. La ventaja de los vínculos en las tres USE, es que las relaciones se dan sin intermediarios representando una oportunidad para fortalecer las relaciones.

\section{Discusión}

Dado que los contextos de las ANP difieren desde su creación en cada país hasta su gestión y manejo, se retomaron aspectos particulares de algunos ejemplos paradigmáticos para discutir los resultados. No hay un caso específico equivalente que integre todos los aspectos considerados en la presente investigación. La situación del APFFNT es coherente con otros estudios realizados en México (Brenner, 2006) que muestran la insuficiencia de los servicios y la infraestructura en relación con la demanda turística. También en el APFFNT, la presencia de los visitantes es efímera y tiene un efecto económico diferenciado según cada comunidad. La mayor afluencia de visitantes se produce en la zona central los fines de semana y durante los días festivos cuando se concentra en unos pocos sitios con atractivos focales (incluido "El Cráter"). Además, muchos actores sociales influyen en la gestión del ANP, pero su falta de relaciones y coordinación impide un mayor aprovechamiento de su potencial turístico.

En el momento de realizar este estudio, el turismo se encuentra en una etapa intermedia de desarrollo, en el que la oferta de servicios turísticos (alojamiento, alimentación y recreación) sigue siendo modesta y los usos dependen de las oportunidades recreativas que los visitantes puedan encontrar en el área protegida. Los sitios estudiados muestran la presencia de una planificación parcial (La Ciénega y Los Venados), formas de control de los flujos de visitantes (Los Venados y El Cráter) y una gestión parcial de las prácticas turísticas (El Cráter). Sin embargo, los resultados muestran que el nivel de organización, coordinación, planificación y 
gestión sigue siendo incompleto. Esto refuerza la idea de que las USE del APFFNT no están completamente estructuradas, aunque tienen los activos en términos de provisión de servicios de recreación, cuyo futuro y efectividad parecen depender del fortalecimiento de las relaciones y la coordinación entre los actores sociales. En este sentido, los resultados se discuten en lo que refiere a la presencia o ausencia de los actores sociales que más resaltaron y por las implicaciones de las relaciones en el manejo de las actividades recreativas.

\subsection{Influencia de la presencia y/o ausencia de actores sociales en sus funciones}

Los resultados de la investigación muestran que no se encontraron todos los actores sociales que deberían estar presentes para un buen manejo de las actividades recreativas, además de que no todos tienen participación activa y permanente. A diferencia de las ANP de algunos países, en los que la participación de instituciones públicas nacionales y regionales desempeña un papel crucial en el desarrollo de proyectos turísticos (Erku -Öztürk y Eraydınm, 2010), en el caso del APFFNT, los resultados muestran la ausencia de órganos rectores para planificar y desarrollar actividades recreativas. Esto se ve reflejado en la limitada oferta de servicios y la precaria calidad de la infraestructura, así como en la falta de proyectos y apoyos para fortalecer las actividades recreativas en las USE.

No obstante que los actores institucionales presentes en el APFFNT han buscado minimizar los impactos negativos de los visitantes y tener en buenas condiciones los sitios, estos se han centrado en la prevención y atención de percances, lo que parece insuficiente para un manejo integral de las actividades recreativas. Los estudios sobre las redes de actores turísticos muestran la importancia de las sinergias sociales en el éxito de los proyectos turísticos (Payen, 2014; van der Zee et al., 2017). Limitaciones como la falta de capital social observada en contextos latinoamericanos (Lopes, Pacheco, Clauzet, Silvano y Begossi, 2015; Morea, 2019; Nunkoo, 2017), así como en otros escenarios políticos y culturales (van der Zee et al., 2017) pueden constituir un factor adverso para el éxito de los proyectos, especialmente los turísticos. En el caso del ANP Antalya, por ejemplo, las Organizaciones No Gubernamentales (ONG's) han hecho contribuciones importantes para el desarrollo y orientación de las actividades turísticas (Erkuş-Öztürk y Eraydınm, 2010). Por lo tanto, es importante identificar cómo los actores sociales presentes en un ANP son capaces de afirmar su posición en los proyectos turísticos. El APFFNT se beneficiaría de la coordinación y vinculación de las Secretarías y Direcciones de Turismo en sus tres ámbitos de gobierno (federal, estatal y municipal), ya que las actividades recreativas no se planifican sino solo se controlan, indicando la relevancia de diversificar actores sociales y vincularse con ONG's. La Procuraduría Federal de la Protección al Ambiente (PROFEPA), "encargada del control de normas jurídicas ambientales y de la persecución de delitos respectivos" (Brenner, 2006, p. 241), requiere mayor participación de los actores sociales involucrados en las ANP, como una forma de reducir las prácticas ilegales. Las actividades que realizan los visitantes en los sitios del APFFNT en ocasiones violan los reglamentos establecidos en el Plan de Manejo del ANP, como el acceso a la zona núcleo con vehículos 4x4 o el ingreso con mascotas. Hasta el momento se encuentra desvinculada de las actividades recreativas del socio-ecosistema en estudio y, como en otras ANP mexicanas (Brenner, 2006), no hay quién sancione a quienes incurren en alguna falta que vulnere el ecosistema.

Los resultados exponen a los actores sociales en diferentes escalas geográficas y múltiples niveles (nacional, estatal, regional, municipal y ejidal); al respecto Calvet-Mir et al. (2015) han identificado este aspecto, por una parte, como favorable para establecer condiciones necesarias para la cooperación, el aprendizaje y la toma de decisiones; por otro lado, como obstaculizador de la coordinación y el consenso entre los actores sociales como sucede en el APFFNT. En este caso, la academia ha contribuido con aportaciones científicas y técnicas referentes a la conservación de los recursos naturales al igual que en el ANP de Monterrey, México (De la Mora-De la Mora, 2015). En el APFFNT la presencia y participación activa del Instituto Tecnológico de Toluca (ITT) en conjunto con la CONANP, CEPANAF, MAT (Medio Ambiente Toluca) y MAZ (Medio Ambiente Zinacantepec) han sido clave para la conservación de recursos naturales y el desarrollo de las actividades recreativas. En la zona montana de "El Cráter" han controlado el acceso a las lagunas, atendiendo algunos temas de contaminación, degradación y erosión causados por los visitantes. Particularmente, la UAEMex (Universidad Autónoma del Estado de México) ha asesorado a las instituciones públicas en temas relacionados con el potencial de los recursos naturales para las actividades recreativas, en la conservación y gestión del ANP, así como en la elaboración de su Plan de Manejo. Adicionalmente, la Red Mexicana de Investigación Ecológica de Largo Plazo (Red Mex-LTER $)^{7}$ sugiere que la presencia de la academia ha sido positiva favoreciendo la generación de información científica para la creación del ANP y el diseño e implementación de programas de manejo (Maass et al., 2010) al crear vínculos entre actores institucionales. 
La presencia de los actores sociales organizados ESJH y ELA juega un rol primordial como propietarios y poseedores de tierras dentro del ANP, donde se realizan actividades recreativas bajo la toma de decisiones en asambleas, que puede o no realizarse siempre acatando la normatividad vigente al ser un APFF, situación que se presenta en varias ANP de México (Brenner, 2006; Pérez, Zizumbo y González, 2009; Riemann, Santes-Álvarez y Pombo, 2011; Vargas, 1997). Estas funciones de los actores sociales se diferencia de países como Canadá y Estados Unidos (Payen, 2014), donde el gobierno es el principal propietario de los territorios en los cuales se insertan las ANP y quien decide sobre lo que se hace en éstas; sin embargo, a pesar de este marco general, el gobierno canadiense creó la designación específica "Reserva del Parque Nacional", para adaptar su gestión a las reivindicaciones indígenas sobre la propiedad o el uso de algunas áreas protegidas para desarrollar actividades tradicionales, y con ello imaginar "regímenes de gestión conjunta" que involucren a los actores locales y los pueblos originarios dentro de este tipo de áreas protegidas (Martin, 2011, p. 284). A pesar de las diferentes historias y las distintas trayectorias administrativas, estos países ofrecen ejemplos ilustrativos de cómo la coordinación entre los actores sociales puede estimular las actividades turísticas y el desarrollo territorial en las ANP.

En el caso del APFFNT y en particular de la USE "La Ciénega" los ejidatarios fueron detonantes en la creación del parque ejidal con propósitos ambientales, pero considerando las actividades recreativas como una oportunidad de desarrollo. No obstante, el flujo de visitantes ha disminuido desde su creación por falta de mantenimiento y el desinterés de administraciones ejidales posteriores a las que crearon el parque. Este mismo tipo de función se presentó en el Parque Estatal El Ocotal en México (Pérez et al., 2009) donde el Ejido de Santiago Maxdá solicitó la creación del espacio. Sin embargo, ambos ejemplos no fueron exitosos, a diferencia de La Reserva de la Biosfera de Los Tuxtlas, en Veracruz, México, donde se impulsó una acción por los ejidatarios para promover el ecoturismo como estrategia de desarrollo local y conservación de los ecosistemas naturales. Este desarrollo ha permitido mejorar los proyectos ecoturísticos, de conservación y de fortalecimiento de la identidad cultural, a pesar de la necesidad de avanzar en la cooperación interinstitucional o de incluir la gestión de las áreas protegidas dentro de un proceso de planificación regional en el que participan los actores sociales interesados en el turismo (González y Figueroa, 2010).

La USE "Los Venados" se caracteriza por el hecho de que CEPANAF administra el parque a través de un convenio entre el ejido y el Gobierno del Estado de México y utiliza los ingresos obtenidos para dar mantenimiento del parque (Pérez et al., 2009). Por tanto, ha tenido diversas propuestas de proyectos turísticos, pero debido a las dinámicas sociopolíticas tanto internas (cambios de administración), como externas (cambio de categoría del ANP), no se ha emprendido ninguno hasta el momento. Lo anterior, ilustra que no basta con que la administración o el emprendimiento corresponda a los ejidatarios, ya que los contextos sociopolíticos, tanto interno como externo, juegan un papel importante en la coordinación de los actores sociales y el éxito de los proyectos. Para ir más lejos, se interpreta la situación considerando que la dimensión actual de los proyectos muestra vínculos débiles entre los actores sociales. Éstos revelan la ausencia de relaciones objetivas para cooperar (proyectos en beneficio de todos los actores sociales), por ejemplo, la ausencia de proyectos de desarrollo recreativo que permitan a las comunidades ejidales aumentar sus ingresos, crear puestos de trabajo y mejorar sus condiciones materiales cotidianas, en los que las comunidades agrarias deseen invertir.

Por su parte, las empresas PSTE que son actores sociales externos al territorio, obtienen los mayores ingresos económicos al ser facilitadoras de las actividades recreativas que brindan; sin embargo, sus servicios no se ajustan cabalmente al reglamento del ANP. De acuerdo al Plan de Manejo, se espera que se realice un registro y se pague una tarifa a la administración de dicha ANP antes de desarrollar cualquier actividad económica y turística dentro de éstas. Sin embargo, estos actores sociales empiezan a desempeñar un papel importante aumentando el flujo de visitantes. Aunque la información que brindan del ANP los medios de comunicación y redes sociales como estrategia de marketing no es del todo verídica, en ocasiones ofertan un paisaje lleno de nieve cuando no es temporada invernal, o pesca de trucha en las lagunas del cráter, actividad que está prohibida y amenaza seriamente al ecosistema. Según Brenner (2006) y Eagles, McCool y Haynes (2002), cuando los actores sociales externos a los territorios controlan los segmentos de visitantes más lucrativos se limita el desarrollo económico local y las actividades recreativas son impulsadas por fuerzas externas a las administraciones de las ANP. Es decir, que los actores sociales externos a los territorios obtienen ingresos sin compensar a los actores sociales locales por el aprovechamiento de los recursos naturales, como ocurre en el APFFNT. 


\subsection{Implicaciones de la dinámica relacional en el manejo de actividades recreativas en el APFFNT}

La importancia del análisis de la dinámica relacional radica en la necesidad de profundizar en los factores sociales que afectan el manejo y la provisión de los servicios que brindan los ecosistemas (Balvanera et al., 2016), ya que la manera en la que se relacionen los actores sociales puede ser un elemento que incentive u obstaculice la conservación de la biodiversidad (Mardones, 2017). En este sentido, se identificó que en las relaciones actuales entre los actores sociales no existe equilibrio entre en la coexistencia de las actividades recreativas y la conservación en el socioecosistema del APFFNT, debido a que los vínculos entre los actores sociales no privilegian la planificación de las actividades recreativas, sino que sólo buscan reducir marginalmente sus impactos negativos y controlarlas. La interacción entre actores sociales en la gestión de ANP es un aspecto importante para la conservación de los servicios ambientales (De la Mora-De la Mora, 2015; Mardones, 2017) y culturales (Payen, 2014). A diferencia de otros estudios sobre actores sociales en las ANP donde el sector académico presenta el mayor número de relaciones en redes de conservación como en el caso de Monterrey, México (De la Mora-De la Mora, 2015), o de Antalya, Turquía (Erku -Öztürk y Eraydınm, 2010), donde este tipo de redes están bajo el dominio de departamentos del gobierno central especializados en turismo; en el caso del APFFNT resalta el papel de gobierno federal, a través de CONANP, con el mayor número de relaciones; específicamente, el caso de la USE "El Cráter" se asemeja al Parque Nacional Cumbres de Monterrey, donde las autoridades federales encargadas de gestionar las ANP son las que presentan mayor integración con distintos actores sociales (De la Mora-De la Mora, 2015). Dicha gestión se debe a las relaciones formales establecidas entre organismos gubernamentales y por las funciones normativas y operativas que desarrolla la CONANP, a través del convenio con el Gobierno del Estado de México. En consecuencia, ni los recursos humanos ni el presupuesto han sido suficientes y no se ha descentralizado, por lo que la CEPANAF solo se apega a la zona núcleo "El Cráter" y la CONANP se enfoca en atender aspectos relacionados con las actividades recreativas y la conservación del ANP; es decir, que asume funciones tanto normativas (planificación y regulación) como operativas (información por los visitantes, seguridad, etc.) que implican que se vincule con un mayor número de actores sociales.

Los indicadores de las redes (Tabla 2) muestran que a pesar de que el nivel de centralización es bajo, esto se considera una ventaja al no haber un actor central que domine la red, y que esa situación puede aumentar el intercambio de diferentes tipos de conocimiento, involucrando a las personas en un proceso de aprendizaje continuo (Prell, Hubacek y Reed, 2009). Según Calvet-Mir et al. (2015) han encontrado que el "bajo nivel de centralización puede obstaculizar la capacidad de adaptación a las condiciones cambiantes para hacer frente a los problemas" (p. 5). En el caso de Antequera y Úbeda en España (Merinero y Pulido, 2009) esta situación ha impulsado la coordinación entre los actores sociales para la gestión turística, a diferencia de las tres USE de este estudio donde no ha representado una ventaja. Llegar a un consenso entre todas las partes es difícil por la diversidad de actores sociales, como por ejemplo cuando en el APFFNT se presenta un percance para lograr un consenso entre todos los actores sociales que brindan atención médica pre-hospitalaria ya que la colaboración entorpece las acciones del otro. Otro ejemplo es cuando los ejidos hacen cambios de administración, el proceso de vinculación debe comenzar de cero, debido a la baja disposición para colaborar. La calidad de las relaciones es débil porque estas son puntuales, tal y como sucede en otros sitios con actividades turísticas como Andalucía (Merinero y Pulido, 2009), lo cual se debe a las estancias de corta duración y a actividades turísticas concretas como los pagos para acceder al recurso. En el caso particular de las USE del APFFNT estas solo se relacionan para intercambiar información, el pago del acceso o por el uso de algún servicio, evidenciando una escasa coordinación entre los actores sociales y la ausencia de metas comunes como la gestión y el control de los flujos de visitantes en los sitios más frecuentados (como "El Cráter"), la educación ambiental efectiva y la capacitación de los operadores turísticos y los proveedores de servicios auxiliares (alimentación o alojamiento) y la coordinación de los interesados para desarrollar un plan integral de señalética, por ejemplo.

Rodríguez et al. (2018) han demostrado que una frecuencia baja en las relaciones limita el desarrollo turístico, aspecto que se asemeja con la situación de las tres USE que presentan relaciones esporádicas, por ejemplo, en temporada baja las relaciones se debilitan o desaparecen. Según Merinero y Pulido (2009), en la gestión de destinos turísticos que están en fases emergentes es primordial disponer de relaciones que se mantengan a largo plazo. Relaciones articuladas formalmente son esenciales en la gestión activa de cualquier destino, pero más, en destinos emergentes como el APFFNT. Sin embargo, las USE presentan escasas relaciones formalizadas que se dan entre los actores sociales gubernamentales como requisito administrativo; el caso particular de la CONANP con la CES (Comisión Estatal de Seguridad) quienes han intentado establecer convenios sin formalizarlos porque no saben qué es lo que 
van a convenir. Las relaciones entre los actores sociales en las USE "El Cráter" y "Los Venados" siguen un patrón similar con mayor dinámica relacional (número y relaciones entre actores sociales) que en "La Ciénega", situación que se asemeja con otros sitios turísticos donde se ha demostrado que la dinámica relacional es más elevada (Merinero y Pulido, 2009), ya que las vías de acceso, las instalaciones, la información y los servicios se encuentran en mejores condiciones.

Debido a que las redes establecidas, hasta el momento, son redes de información para evitar percances por el alto flujo de visitantes, es imperativo transitar a redes de colaboración donde los actores sociales asuman corresponsabilidades y establezcan acciones conjuntas para la planificación y manejo de las actividades recreativas, las cuales "son claves para la gobernanza de sistemas socio-ecológicos complejos" (Mardones, 2017, p. 69) y mejoran el establecimiento de políticas de desarrollo (Erku -Öztürk y Eraydınm, 2010).

El hecho de que las relaciones reflejen una incidencia poco favorable para la coexistencia de las funciones ecológicas y recreativas puede explicarse porque dichas actividades recreativas no están siendo planificadas ni controladas. Estas dos actividades no forman parte de las actividades de los actores sociales presentes, aunado a que las relaciones no son formales ni de largo plazo, dependiendo en su mayoría de la estacionalidad del destino. Además, las regiones montañosas como el APFFNT por su mayor fragilidad ecosistémica han sido hasta ahora menos compatibles con el turismo (Stolton, 2010). Por tanto, se demuestra la necesidad de que los actores sociales desarrollen acciones concretas de educación ambiental para todos los usuarios de las zonas protegidas, como lo han hecho la mayoría de las áreas protegidas de América del Norte.

\section{Conclusiones}

El estudio de la dinámica relacional en socio-ecosistemas de las ANP es un tema poco habitual en las investigaciones turísticas, a pesar de que el conocimiento sobre los actores sociales y sus relaciones es un aspecto central para la gestión de las actividades recreativas. El análisis de la dinámica relacional actual dentro de la APFFNT, con énfasis las tres Unidades Socio-Ecológicas que reciben un mayor número de visitantes, muestra que la complementariedad entre las funciones ecológicas y recreativas es todavía incipiente. El carácter mixto del territorio - por un lado tierras comunales, y por otro área protegida con limitados atractivos para los visitantes - lleva a una separación de los intereses de los actores: la CONANP, que maneja el área protegida - incluyendo las actividades turísticas -, está supeditada a su mandato de conservación; las comunidades ejidales, están interesadas en articular las dimensiones ecológica y social en sus prácticas e instalaciones recreativas; y los actores externos (operadores turísticos privados que no residen en el área protegida) están enfocados en los ingresos económicos generados por la actividad recreativa. Así, la dinámica relacional se caracteriza por el hecho de que los actores involucrados no necesariamente comparten objetivos; algunos ejidos buscan generar ingresos para sus comunidades, algunos operadores privados utilizan el recurso según una lógica extractivista, sin respetar las regulaciones previstas en el Plan de Manejo, a lo que se suma la desconexión entre las instituciones especializadas y las reguladoras.

El bajo nivel de centralización identificado en los tres casos sugiere que la ausencia de un actor central evidencia la lógica centrífuga bajo la que opera el APFFNT, reflejando una ineficiencia de la organización territorial actual en términos de desarrollo turístico. Lo anterior, al remitirse a una perspectiva post-estructuralista, muestra la relevancia del Análisis de Redes Sociales para comprender el modo en que los actores sociales entablan sus relaciones - a través de los medios de producción, los valores intrínsecos o específicos movilizados por el turismo - vinculadas al capital natural y cultural del territorio. Ello muestra que las posiciones de poder y dependencia frecuentemente son renegociadas por las partes interesadas, lo que confirma la exacerbación de los conflictos entre las partes interesadas en el contexto de la reciente modificación de la categoría del ANPFFNT (Héritier y Lebreton, 2017). El análisis de los vínculos revela la forma en que las representaciones de las partes interesadas, su posición dentro de la red relacional y las estrategias que implementan juegan un papel preponderante para lograr una agencia real. Las tensiones subyacentes entre los actores sociales y la escasa congruencia de los objetivos de desarrollo del turismo en él han sido, hasta ahora, un obstáculo para las acciones de desarrollo en el territorio.

Para superar esta situación, podría ser útil reducir la distancia de los vínculos y fortalecer el tipo de relaciones entre los actores sociales encargados de la gestión de los visitantes y los prestadores de servicios turísticos especializados, que son los que desarrollan las actividades recreativas en las USE del 
APFFNT. Se deben incrementar las relaciones entre los visitantes y los actores sociales que gestionan los recursos, así como reconstruir la confianza para que los proyectos que se planteen tengan mayor éxito, haciendo más eficiente la gestión turística del territorio. El análisis de la dinámica relacional permitió examinar la complejidad del manejo del APFFNT, generando información que puede ayudar a orientar planes, programas o estrategias compatibles entre conservación y aprovechamiento para el manejo de las actividades recreativas en el ANP. La comprensión de las características de las relaciones sociales mejora la identificación de los límites y bloqueos que permanecen entre los actores, abre perspectivas para mejorar las estrategias o planes de conservación, como se ha demostrado en otros contextos, pero también podría conducir a la creación de condiciones para mejorar la gestión de los recursos naturales y la conservación de la biodiversidad.

\section{Agradecimientos}

Al Consejo Nacional de Ciencia y Tecnología (CONACYT) de México por el financiamiento para: (i) la autora Nadinne Ivette González Romero en el Doctorado en Ciencias Agropecuarias y Recursos Naturales de la Universidad Autónoma del Estado de México; y (ii) el proyecto de investigación Parque Nacional Nevado de Toluca: un laboratorio socio-ambiental en la innovación de políticas para la gestión de parques nacionales, en el marco del Convenio Bilateral México (CONACYT) - Francia (ANR).

\section{Bibliografía}

Artesi, L. 2007. Desarrollo local y turismo. Notas sobre nuevos enfoques teóricos y metodológicos para la implementación de políticas en la Patagonia Austral. En Zárate, R. y Artesi, L. (Eds.) Ciudadanía, Territorio y Desarrollo Endógeno. Resistencias y Mediaciones de las Políticas Locales en las Encrucijadas del Neoliberalismo (pp. 347-362). Buenos Aires, Argentina: Biblos.

Baggio, R., Scott, N., y Cooper, C. 2010. Network science: A Review Focused on Tourism. Annals of Tourism Research, 37(3), 802-827. doi: 10.1016/j.annals.2010.02.008

Balvanera, P., Arias-González, J. E., Rodríguez-Estrella, R., Almeida-Leñero, L., y Schmitter-Soto, J. J. (Eds.). 2016. Una mirada al conocimiento de los ecosistemas de México. Ciudad de México, México: Universidad Nacional Autónoma de México.

Ban, N. C., Mills, M., Tam, J., Hicks, C. C., Klain, S., Stoeckl, N., Bottrill, M. C., Levine, J., Pressey, R. L., Satterfield, T., y Chan, K. M. 2013. A social-ecological approach to conservation planning: Embedding social considerations. Frontiers in Ecology and the Environment, 11(4), 194-202. doi: $10.1890 / 110205$

Bennett, N. J., Roth, R., Klain, S. C., Chan, K., Christie, P., Clark, D. A., Cullman, G., Curran, D., Durbin, T. J., Epstein, G., Greenberg, A., Nelson, M. P., Sandlos, J., Stedman, R., Teel, T. L., Thomas, R., Veríssimo, D., y Wyborn, C. 2017. Conservation Social Science: Understanding and Integrating Human Dimensions to improve Conservation. Biological Conservation, (205), 93-108. doi: 10.1016/j. biocon.2016.10.006

Brechin, S. R., Wilshusen, P. R., Fortwangler, C. L., y West, P. C. 2002. Beyond the Square Wheel: Toward a More Comprehensive Understanding of Biodiversity Conservation as Social and Political Process. Society \& Natural Resources, 15(1), 41-64. doi: 10.1080/089419202317174011

Brenner, L. 2006. Áreas naturales protegidas y ecoturismo: el caso de la Reserva de la Biosfera Mariposa Monarca, México. Relaciones. Estudios de historia y sociedad, 27(105), 237-265. Recuperado de http:// www.redalyc.org/articulo.oa?id=13710508

Burgos, D. A. 2014. El Papel de las Redes Sociales en el Desarrollo de Prácticas Turísticas Sostenibles: algunas reflexiones teóricas. Turismo em Análise, 25(1), 75-101.

Calvet-Mir, L., Maestre-Andrés, S., Molina, J., y van den Bergh, J. 2015. Participation in protected areas: a social network case study in Catalonia, Spain. Ecology and Society, 20(4), 45. doi: 10.5751/ ES-07989-200445

Casanueva, C., Gallego, A., y García-Sánchez, M.R. 2016. Social Network Analysis in Tourism. Current Issues in Tourism, 19(12), 1190-1209. doi: 10.1080/13683500.2014.990422

Ceballos, G. 2011. Propuesta de recategorización y decreto del Parque Nacional Nevado de Toluca. Toluca, México: Secretaría del Medio Ambiente. Gobierno del Estado de México. 
Comisión Nacional de Áreas Naturales Protegidas [CONANP] 2013. Borrador del programa de manejo del APFF Nevado de Toluca. México: Comisión Nacional de Áreas Naturales Protegidas, Secretaría de Medio Ambiente y Recursos Naturales.

Comisión Nacional de Áreas Naturales Protegidas [CONANP] 2016. Programa de Manejo. Área Natural Protegida con categoría de Área de Protección de Flora y Fauna Nevado de Toluca. México: Secretaría de Medio Ambiente y Recursos Naturales.

Crona, B., y Bodin, Ö. 2006. What you know is Who you know? Communication Patterns among Resource Users as a Prerequisite for Co-Management. Ecology and Society, 11(2), 7. Recuperado de http:// www.ecologyandsociety.org/vol11/iss2/art7/

Cruz, E., y Velázquez, J. A. 2020. Gobernanza, Turismo y Redes de Colaboración: El Parque Nacional El Chico, México. Revista Espacios, 41(5), 1-13. Recuperado de http://www.revistaespacios.com/ a20v41n05/20410516.html

De la Mora-De la Mora, G. 2015. Redes sociales y Áreas Naturales Protegidas en la Zona Metropolitana de Monterrey, Nuevo León. Economía, Sociedad y Territorio, 15(49), 747- 778.

de Oliveira Inácio, R., Reis Xavier, T., Cabral Flecha, A., y Wittmann, M. 2012. Redes del turismo. La dinámica de las conexiones de la ciudad de Ouro Preto - Brasil. Estudios y Perspectivas en Turismo, $21(2), 495-514$.

Dedeke, A. (Nick). 2017. Creating Sustainable Tourism Ventures in Protected Areas: An Actor-Network Theory Analysis. Tourism Management, (61), 161-172. doi: 10.1016/j.tourman.2017.02.006

Diario Oficial de la Federación [DOF] 2016. Resumen del Programa de manejo del APFF Nevado de Toluca. México: Comisión Nacional de Áreas Naturales Protegidas, Secretaría de Medio Ambiente y Recursos Naturales. Disponible en: http://cofemersimir.gob.mx/expediente/18890/mir/39941/ regulacion/2510107

Dredge, D. 2006. Policy networks and the local organisation of tourism. Tourism Management, 27(2), 269-280. doi: 10.1016/j.tourman.2004.10.003

Eagles, P. F., McCool, S. F. y Haynes, C. D. 2002. Sustainable Tourism in Protected Areas: Guidelines for Planning and Management. Gland, Switzerland, and Cambridge, UK: IUCN.

Endter-Wada, J., Blahna, D., Krannich, R., y Brunson, M. 1998. A Framework for Understanding Social Science Contributions to Ecosystem Management. Ecological Applications, 8(3), 891-904. doi: 10.1 890/1051-0761(1998)008[0891:AFFUSS]2.0.CO;2

Erkuş-Öztürk, H., y Eraydın, A. 2010. Environmental Governance for Sustainable Tourism Development: Collaborative Networks and Organisation Building in the Antalya Tourism Region. Tourism Management, (31), 113-124. doi: 10.1016/j.tourman.2009.01.002

Esquivel Rios, S., Cruz Jiménez, G., Zizumbo Villarreal, L., y Cadena Inostroza, C. 2014. Gobernanza para el turismo en espacios rurales. Reserva de la biosfera mariposa Monarca. Revista Mexicana de Ciencias Agrícolas, 5(9; especial), 1631-1643. doi: 10.29312/remexca.v0i9.1053

Franco-Maass, S., Osorio-García, M., Nava-Bernal, G., y Regil-García, H. H. 2009. Evaluación multicriterio de los recursos turísticos, Parque Nacional Nevado de Toluca, México. Estudios y Perspectivas en Turismo, (18), 208-226.

González, A. A., y Figueroa, A. 2010. Ecoturismo en la Reserva de la Biosfera Los Tuxtlas. En Carabias, J., Sarukhán, J., de la Maza, J., y Galindo, C. al. (Eds.). Patrimonio natural de México. Cien casos de éxito. México: Comisión Nacional para el Conocimiento y Uso de la Biodiversidad.

González Romero, N. I. 2018. Dinámica relacional de las actividades recreativas en el Área de Protección de Flora y Fauna Nevado de Toluca. Tesis doctoral. Posgrado en Ciencias Agropecuarias y Recursos Naturales. Universidad Autónoma del Estado de México, México.

González-Romero, N., Galicia, L., Arteaga-Reyes, T.T., Thomé-Ortiz, H., y Héritier, S. 2018. Actividades recreativas y conservación en Áreas Naturales Protegidas en el centro de México: un enfoque desde los Socioecosistemas. Ecosistemas, 27(1), 116-126. doi: 10.7818/ECOS.1407; http://www.revistaecosistemas. net/index.php/ecosistemas/article/view/1407

Goodman, L. 1961. Snowball Sampling. Annals of Mathematical Statistics, (32), 148-170. Recuperado de https://projecteuclid.org/download/pdf_1/euclid.aoms/1177705148

Guerrero, A. M., McAllister, R. R. J., Corcoran, J., y Wilson, K. A. 2013. Scale Mismatches, Conservation Planning, and the Value of Social-Network Analyses. Conservation Biology, 27(1), 35-44. doi: 10.1111/j.1523-1739.2012.01964.x

Hanneman, R.A., y Riddle, M. 2000. Introducción a los métodos del análisis de redes sociales. Edición traducida por Revista REDES. Revista. Versión electrónica disponible en http://revista-redes. 
rediris.es/webredes/text.htm [Original en inglés: https:/faculty.ucr.edu/ hanneman/nettext/Introduction_to_Social_Network_Methods.pdf]

Héritier, S., y Lebreton, C. 2017. From 'Revolutionary' to Contested Park. Mobilization and Conflicts in the Recategorization Process of the Nevado de Toluca National Park (Mexico). Revue de Sciences Humaines, 16, 1-17. doi: 10.4000/articulo.3279

Jiménez Martínez, A. de J. 2005. Una aproximación a la conceptualización del turismo desde la teoría general de sistemas. México: Universidad del Caribe / Porrúa.

Latour, B. 2019. Cara a cara con el planeta: Una nueva mirada sobre el cambio climático alejada de las posiciones apocalipticas. México: Siglo Veintiuno.

Laumann, E. O., Marsden, P. V., y Prensky, D. 1983. The Boundary Specification Problem in Network Analysis. En Burt y Minor (Eds), Applied Network Analysis: A Methodological Introduction. (pp. 61-86). Beverly Hills, California: Sage Publications.

Leff, E. 2000. Pensar la complejidad ambiental. En Leff Enrique (Ed.), La complejidad ambiental (pp. 7-53). México: Siglo Veintiuno.

Leung, Y.-F., Spenceley, A., Hvenegaard G., y Buckley, R. 2015. Tourism and Visitor Management in Protected Areas: Guidelines towards sustainability. Best Practice Protected Area Guidelines. Gland, Switzerland: IUCN. Series No. XX.

Lopes, P. F. M., Pacheco, S., Clauzet, M., Silvano, R. A. M., y Begossi, A. 2015. Fisheries, Tourism, and Marine Protected Areas: Conflicting or Synergistic Interactions? Ecosystem Services, (16), 333-340. doi: 10.1016/j.ecoser.2014.12.003

Maass, J. M., Jardel, E. J., Martínez-Yrízar, A., Calderón-Aguilera, L. E., Herrera, J., Castillo, A., Euán-Ávila, J., y Equihua, M. 2010. Las áreas naturales protegidas y la investigación ecológica de largo plazo en México. Ecosistemas, 19(2), 69-83. Recuperado de http://www.revistaecosistemas.net/ index.php/ecosistemas/article/view/47

Maass, M., Balvanera, P., Bourgeron, P., Equihua, M., Baudry, J., Dick, J., Forsius, M., Halada, L., Krauze, K., Nakaoka, M., Orenstein, D. E., Parr, T. W., Redman, C. L., Rozzi, R., Santos-Reis, M., Swemmer, A. M., y Vădineanu, A. 2016. Changes in biodiversity and trade-offs among ecosystem services, stakeholders, and components of well-being: The contribution of the International Long-Term Ecological Research network (ILTER) to Programme on Ecosystem Change and Society (PECS). Ecology and Society, 21(3), 1-31. doi: 10.5751/ES-08587-210331

Mardones, G. 2017. Análisis de redes sociales para la gobernanza de un área protegida y su zona de amortiguación en el bosque templado del sur de Chile. Revista Hispana para el Análisis de Redes Sociales, 28(1), 61-72. doi: 10.5565/rev/redes.690

Martin, B. 2011. Negotiating a Partnership of Interests: Inuvialuit Land Claims and the Establishment of Northern Yukon (Ivvavik) National Park. En Campbell, C.E. (ed.). A Century of Parks Canada (pp.1911-2011). Calgary, Canada: University of Calgary.

Martini, U., y Buffa, F. 2015. Local networks, stakeholder dynamics and sustainability in tourism. Opportunities and limits in the light of stakeholder theory and SNA. Sinergie Italian Journal of Management, 33(96), 113-130. doi: 10.7433/s96.2015.07

Martín-López, B., Palomo, I., García-Llorente, M., Iniesta-Arandia, I., Castro, A. J., García Del Amo, D., Gómez-Baggethun, E., y Montes, C. 2017. Delineating boundaries of social-ecological systems for landscape planning: A comprehensive spatial approach. Land Use Policy, (66), 90-104. doi: 10.1016/j. landusepol.2017.04.040

Merinero, R. R., y Pulido F. J. I. 2009. Desarrollo turístico y dinámica relacional. Metodología de análisis para la gestión activa de destinos turísticos. Cuadernos de Turismo, (23), 173-193. Recuperado de https://revistas.um.es/turismo/article/view/70091

Merinero, R. R., y Zamora, A. E. 2009. Colaboración entre los actores sociales turísticos en ciudades patrimoniales. Reflexiones para el análisis del desarrollo turístico. PASOS Revista de Turismo y Patrimonio Cultural, 7(2), 219-238. doi: 10.25145/j.pasos.2009.07.015

Morea, J. P. 2019. A framework for improving the management of protected areas from a social perspective: The case of Bahía de San Antonio Protected Natural Area, Argentina. Land Use Policy, (87), 1-11. doi: 10.1016/j.landusepol.2019.104044

Nordin, S. 2003. Tourism Clustering and Innovation: path to economic growth and development. Osternsund, Sweden: European Tourism Research Institute, MID - Sweden University.

Nunkoo, R. 2017. Governance and Sustainable Tourism: What is the Role of Trust, Power and Social Capital? Journal of Destination Marketing \& Management, 6(4), 277-285. doi: 10.1016/j.jdmm.2017.10.003 
Payen, A. 2014. Los habitantes: ¿actores sociales del desarrollo en los proyectos de dinamización turística? Caso del Parque Nacional de Loango en Gabón. Via, Tourism Review [Online], (4-5), 1-15. doi: 10.4000/viatourism. 886

Pérez, R. C., Zizumbo, L., y González, V. M. 2009. Impacto ambiental del turismo en áreas naturales protegidas; procedimiento metodológico para el análisis en el Parque Estatal El Ocotal, México. El Periplo Sustentable, (16), 25-56.

Prell, C., Hubacek, K., y Reed, M. 2009. Stakeholder Analysis and Social Network Analysis in Natural Resource Management. Society and Natural Resources, 22(6), 501-518. doi: 10.1080/08941920802199202

Pulido, F. J. I., y López, S. Y. 2012. La necesidad de modelos turísticos sostenibles en espacios rurales y naturales. En Rivera, M. M. y Rodríguez, G. L. (Eds.), Turismo responsable, sostenibilidad y desarrollo local comunitario. (pp. 99-116). Córdoba: Cátedra Intercultural, Universidad de Córdoba, España: AECIT, AACID y Unión Europea (POCTEFEX-BIOECONOMY).

Ramírez de la Cruz, E., y Gómez, F. E. 2016. Apartado Metodológico. Términos y fundamentos básicos del análisis de redes sociales. En Ramírez de la Cruz, y Edgar, E. (Ed.), Análisis de redes sociales para el estudio de la gobernanza y las políticas públicas: aproximaciones y casos. México, D.F.: Centro de Investigación y Docencia Económicas.

Rendón, M. R., Aguilar, Á. J., Muñoz, R. M., y Altamirano, C. J. R. 2007. Identificación de actores sociales clave para la gestión de la innovación: el uso de redes sociales. México: Universidad Autónoma Chapingo-Ciestaam/PIIAI: Serie Materiales de formación para las Agencias de Gestión de la Innovación.

Riemann, H., Santes-Álvarez, R. V., y Pombo, A. 2011. El papel de las áreas naturales protegidas en el desarrollo local: El caso de la península de Baja California. Gestión y Política Pública, 20(1), 141-172.

Rodríguez Zermeño, G., y Zizumbo Villarreal, L. 2009. Desarrollo Turístico y Capacidades Colectivas en San Juan de Las Huertas, Zinacantepec, México. Turismo em Análise, 20(2), 263-281.

Rodríguez, I., Pulido, J. I., Vargas, A., y Shaadi, R. M. 2018. Dinámica relacional en los pueblos mágicos de México. Estudio de las implicaciones de la política turística a partir del análisis de redes. Turismo y Sociedad, (22), 85-104. doi: 10.18601/01207555.n22.05

Scott, N., Baggio, R., y Cooper, C. 2008. Network Analysis and Tourism: From Theory to Practice. Clevedon, UK: Channel View Publications.

Stolton, S. 2010. Protected Areas: Linking Environment and Well-Being. En Stolton, S., Dudley, N. (Eds.), Arguments for Protected Areas: Multiple Benefits for Conservation and Use (pp. 1-12). London, UK: Earthscan.

Tarrío, G. M., y Concheiro, B. L. 2006. Chiapas: los cambios en la tenencia de la tierra. Argumentos, 19(51), 31-71.

Toledo, V. M. 1996. Saberes indígenas y modernización en América Latina. Etnoecológica, (4-5), 135-148.

Toledo, V. M., y Barrera-Bassols, N. 2011. Saberes tradicionales y adaptaciones ecológicas en siete regiones indígenas de México. En Reyes Escutia, F., y Barrasa García, S. (Eds.), Saberes ambientales campesinos. Cultura y naturaleza en comunidades indígenas y mestizas de México (pp. 15-60). Tuxtla Gutiérrez, Chiapas: Universidad de Ciencias y Artes de Chiapas.

Vallejo Valencia, B., y Osorio García, M. 2013. Análisis Social Sobre los Habitantes de la Comunidad de La Peñuela, Parque Nacional Nevado de Toluca, México. Estudios y Perspectivas en Turismo, 22(3), 425-449.

van der Zee, E., y Vanneste, D. 2015. Tourism networks unravelled; a review of the literature on networks in tourism management studies. Tourism Management Perspectives, (15), 46-56. doi: 10.1016/j.tmp.2015.03.006

van der Zee, E., Gerrets, A.-M., y Vanneste, D. 2017. Complexity in the Governance of Tourism Networks: Balancing between External Pressure and Internal Expectations. Journal of Destination Marketing and Management, 6(4), 296-308. doi: 10.1016/j.jdmm.2017.07.003

Vandermeer, J., y Perfecto. I. 2003. The Agricultural Matrix and a future Paradigm for Conservation. Conservation Biology, 21(1), 274-277. doi: 10.1111/j.1523-1739.2006.00582.x

Vargas, M. F. 1997. Parques Nacionales de México. México: Instituto Nacional de Ecología, Secretaría de Medio Ambiente y Recursos Naturales.

Vargas, M.A., y Rodríguez, H.I. 2014. Dinámica relacional de la gestión turística en el pueblo mágico de Calvillo, Aguascalientes, México. Teoría y Praxis, 9(especial), 137-160.

Verd Pericás, J. M., y Martí Olivé, J. 1999. Muestreo y recogida de datos en el análisis de redes sociales. Qüestiió, 23(3), 507-524.

Wasserman, S., y Faust, K. 2013. Análisis de Redes Sociales. Métodos y aplicaciones. Madrid, España: Centro de Investigaciones Sociológicas (CIS). 


\section{Notas}

1 Algunos estudios de geografía del turismo consideran a la recreación como el medio para designar el uso del tiempo libre, tomando la forma de ocio y turismo. El ocio se asocia a los espacios de la vida cotidiana, mientras que el turismo se refiere al espacio de lo no cotidiano e implica (para utilizar parte de la definición de la Organización Mundial del Turismo) hacer un viaje de un día (excursionismo) o pasar una noche fuera de casa.

2 La voluntad de los actores sociales de establecer relaciones está vinculada al grado de desarrollo del turismo. De hecho, Merinero y Pulido (2009) han demostrado que el grado de desarrollo aumenta a medida que acrecenta la intensidad de las relaciones.

3 La noción de socio-ecosistema implica que las sociedades humanas no son sólo usuarias de los recursos del ecosistema. Por el contrario, sus diferentes componentes - humanos y no humanos - "coevolucionan a través de procesos biofísicos y sociales que ocurren a diferentes escalas de espacio y tiempo" (Maass et al., 2016, p. 4). En contraste con una concepción utilitaria de los recursos, la "capacidad de actuar" (agency), para utilizar las palabras del filósofo Bruno Latour (2019) se considera como elemento fundador de dicha relación.

4 Bajo un enfoque de socioecosistemas Martín-López et al. (2017) establecieron como "Unidades Socio-Ecológicas" las interacciones entre los subsistemas natural y social a escala local. En este sentido, se considera al APFFNT un socio-ecosistema compuesto por distintas USE, que presentan interacciones a través de las actividades recreativas y donde los vínculos entre los actores sociales involucrados en el manejo de dichas actividades están teniendo efectos sobre los sistemas naturales.

5 En México, las formas de tenencia de la tierra se clasifican en: ejidal, comunal, federal y propiedad privada. La ejidal y comunal corresponden a tierras otorgadas por el gobierno a la población campesina a partir de la Revolución de 1910, como respuesta a las disputas e inconformidad de los campesinos (Tarrío y Concheiro, 2006); la federal refiere a las tierras que pertenecen al gobierno y la propiedad privada a particulares. Los recursos (forestales, hídricos y agrícolas) siguen siendo la base de la economía de las comunidades de los ejidos. En el APFFNT, estas comunidades han desarrollado su conocimiento de los ecosistemas mediante el desarrollo de mecanismos de manejo comunitario (en particular para el agua y los bosques).

6 Información actualizada a la fecha de realización del trabajo de campo y la aplicación de entrevistas.

7 "LTER: Long Term Ecological Research" son grupos académicos de colaboración científica, comprometidos a generar y compartir información, producto del seguimiento de procesos ecológicos durante muchos años (Maass et al., 2010). 